\title{
Artifacts in measuring aerosol uptake kinetics: the roles of time, concentration and adsorption
}

\author{
L. H. Renbaum and G. D. Smith \\ Department of Chemistry, University of Georgia, Athens, Georgia, USA \\ Received: 1 March 2011 - Published in Atmos. Chem. Phys. Discuss.: 9 March 2011 \\ Revised: 7 July 2011 - Accepted: 8 July 2011 - Published: 18 July 2011
}

\begin{abstract}
In laboratory studies of organic aerosol particles reacting with gas-phase oxidants, high concentrations of radicals are often used to study on the timescale of seconds reactions which may be occurring over days or weeks in the troposphere. Implicit in this approach is the assumption that radical concentration and time are interchangeable parameters, though this has not been established. Here, the kinetics of $\mathrm{OH}-$ and $\mathrm{Cl}$-initiated oxidation reactions of model singlecomponent liquid (squalane) and supercooled (brassidic acid and 2-octyldodecanoic acid) organic aerosols are studied by varying separately the radical concentration and the reaction time. Two separate flow tubes with residence times of 2 and $66 \mathrm{~s}$ are used, and $[\mathrm{OH}]$ and $[\mathrm{Cl}]$ are varied by adjusting either the laser photolysis fluence or the radical precursor concentration $\left(\left[\mathrm{O}_{3}\right]\right.$ or $\left[\mathrm{Cl}_{2}\right]$, respectively) used to generate the radicals. It is found that the rates measured by varying the radical concentration and the reaction time are equal only if the precursor concentrations are the same in the two approaches. Further, the rates depend on the concentrations of the precursor species with a Langmuir-type functional form suggesting that $\mathrm{O}_{3}$ and $\mathrm{Cl}_{2}$ saturate the surface of the liquid particles. It is believed that the presence of $\mathrm{O}_{3}$ inhibits the rate of $\mathrm{OH}$ reaction, perhaps by reacting with $\mathrm{OH}$ radicals or by $\mathrm{O}_{3}$ or intermediate species blocking surface sites, while $\mathrm{Cl}_{2}$ enhances the rate of $\mathrm{Cl}$ reaction by participating in a radical chain mechanism. These results have important implications for laboratory experiments in which high concentrations of gas-phase oxidants are used to study atmospheric reactions over short timescales and may explain the variability in recent measurements of the reactive uptake of $\mathrm{OH}$ on squalane particles in reactor systems used in this and other laboratories.
\end{abstract}

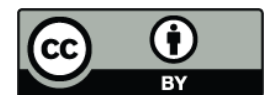

Correspondence to: G. D. Smith (gsmith@chem.uga.edu)

\section{Introduction}

Aerosols are important constituents of the Earth's atmosphere due to their role in climate (Charlson et al., 1989; Hobbs, 1993; Park et al., 2005; Park and Jeong, 2008), atmospheric chemistry (Andreae and Crutzen, 1997), visibility (Baumer et al., 2008; Eidels-Dubovoi, 2002) and human health (Avol et al., 1979; Ondov et al., 2004; Penn et al., 2005). Organic matter in tropospheric aerosols comprises $10-90 \%$ of the fine particulate mass (Andreae and Crutzen, 1997; Putaud et al., 2004; Saxena and Hildemann, 1996). Heterogeneous aging of organic aerosols by atmospheric oxidants such as hydroxyl radicals, nitrate radicals and ozone may modify aerosol properties such as the ability to directly scatter and absorb solar radiation and the ability to act as nuclei for cloud condensation which may indirectly influence the Earth's radiation balance. The rates at which heterogeneous oxidation processes proceed and the products formed as a result of these reactions has become a topic of recent research interest as they can influence the fate and properties of organic aerosols in the troposphere.

Among the most important oxidants responsible for atmospheric radical-initiated oxidation of organic particles in the troposphere are hydroxyl radicals $(\mathrm{OH})$. Chlorine radicals $(\mathrm{Cl})$ are also commonly used as a proxy for $\mathrm{OH}$ radicals in the laboratory because they generally react by a similar mechanism and can be generated in higher concentrations, though their significance in the atmosphere is limited. Multiple experiments have shown that both $\mathrm{OH}$ and $\mathrm{Cl}$ reactions with organic aerosols are very efficient with reactive uptake coefficients (the probability that radical-particle collision will result in reaction) between 0.1 and 3.0 (Bagot et al., 2008; Bertram et al., 2001; Cooper and Abbatt, 1996; George et al., 2007; Hearn and Smith, 2006; Hearn et al., 2007; Kessler et al., 2010; Lambe et al., 2007; Liu et al., 2011; McNeill et al., 2008; Moise and Rudich, 2001; Molina et al., 2004).

Published by Copernicus Publications on behalf of the European Geosciences Union. 
Numerous experiments have suggested that secondary chemistry may play an important role in the rapid reactive uptake of radical species into organic aerosol. The reactive uptake coefficient of $\mathrm{Cl}$ (Hearn et al., 2007) and $\mathrm{OH}$ (Hearn and Smith, 2006; George et al., 2007) on dioctyl sebacate sebacate (DOS) particles has been reported to be greater than unity, and the authors have suggested secondary radical chemistry to explain the rapid loss rate of DOS in these particles. Similarly, Liu et al. (2011) have measured $\mathrm{Cl}$ uptake coefficients as large as 3.0 on squalane particles and have attributed some of the observed reaction to secondary chemistry. Smith et al. (2009) and Che et al. (2009) have also measured the reactive uptake of $\mathrm{OH}$ on squalane particles in two separate reaction chambers that differed in the amount of reaction time and found that at shorter times $(\sim 37 \mathrm{~s})$ and average $\mathrm{OH}$ concentrations of $1 \times 10^{10}$ molecules $\mathrm{cm}^{-3}$, the reactive uptake of $\mathrm{OH}$ was $0.3 \pm 0.07$ (Smith et al., 2009) whereas at longer times $(1.5-3 \mathrm{~h})$ and lower $\mathrm{OH}$ concentrations (1$7 \times 10^{8}$ molecules $\mathrm{cm}^{-3}$ ) the reactive uptake was $0.51 \pm 0.10$ (Che et al., 2009). As a possible explanation of the different reactive uptakes measured in these two experiments, Che et al. (2009) have suggested the importance of a secondary loss mechanism at low $\mathrm{OH}$ concentrations whereby a radical intermediate, such as $\mathrm{RO}$ or $\mathrm{RO}_{2}$, may abstract a hydrogen from squalane.

A kinetic model, devised by McNeill et al. (2008), predicts that due to secondary radical chemistry and surface renewal processes, decay kinetics may be observed in which time and concentration are not interchangeable variables. This model suggests that laboratory studies employing high radical concentrations $\left(10^{10}-10^{12}\right.$ molecules $\left.\mathrm{cm}^{-3}\right)$ and short times (seconds to minutes) may not be representative of reactions which occur in the troposphere with much smaller concentrations $\left(\sim 10^{6}\right.$ molecules $\left.\mathrm{cm}^{-3}\right)$ and long interaction times (days to weeks). Furthermore, in their recent study of $\mathrm{Cl}$ uptake by squalane particles, Liu et al. (2011) conclude that time and oxidant concentration are not interchangeable kinetic parameters when secondary chain chemistry is active. However, it is still an open question as to whether time and concentration are equivalent variables in organic aerosol oxidation kinetics in the absence of a radical chain or involving $\mathrm{OH}$ radicals, instead.

In the present work, whether radical concentration and time are interchangeable variables during the $\mathrm{OH}$ and $\mathrm{Cl}$-initiated oxidation reactions of squalane $(\mathrm{Sq}), 2-$ ocyldodecanoic acid (2-ODA) and brassidic acid (BA) particles is explored. Two different reactor flow tubes, varying in the internal volume and in the reactant interaction time by a factor of 33, were used to measure the kinetics in two ways: by changing reaction time and by changing radical concentration. To achieve the same radical exposure $([\mathrm{OH}] \cdot t$ or $[\mathrm{Cl}] \cdot t)$ in the two flow tube systems, the radical concentration was varied by the same factor. Further, the influences that the radical precursors $\left(\mathrm{O}_{3}\right.$ and $\left.\mathrm{Cl}_{2}\right)$ have on the measured rates of these reactions are investigated through a system- atic study of 2-ODA oxidation as a function of the precursor concentration. Squalane and 2-ODA were chosen for these experiments because they are both branched species which may form liquid particles at room temperature and are representatives of branched, saturated organic molecules found in ambient aerosols. Brassidic acid is an unbranched, unsaturated fatty acid that is able to be supercooled at room temperature (Renbaum and Smith, 2009a, b) and is representative of unsaturated fatty acids in ambient aerosols. Also, all three species have low vapor pressures at room temperature thus making them amenable to studying the heterogeneous reactions between gas-phase oxidants and condensed phase organics.

\section{Materials and methods}

\subsection{Particle generation}

Particles of Sq, 2-ODA and BA were generated through homogeneous nucleation by flowing $0.9 \mathrm{slpm}$ (standard liters per minute) of $\mathrm{N}_{2}$ through a reservoir containing either $\mathrm{Sq}$, 2-ODA or BA heated to $135-145^{\circ} \mathrm{C}$. The aerosol was then reheated as it flowed through $1 / 2$-inch o.d. glass tubing (4 inches long, $250^{\circ} \mathrm{C}$ ). Typically, reheating of the aerosol results in narrowing of the particle size distribution from a geometric standard deviation (gsd) of $\sim 1.4$ to a gsd of $\sim 1.2$. As both 2-ODA and BA are solids at room temperature with melting points of $34-36^{\circ} \mathrm{C}$ (Knothe, 2002) and $58-59^{\circ} \mathrm{C}$ (Chang and Miwa, 1972), respectively, their vapor nucleated and formed supercooled liquid droplets as they cooled to room temperature. Previous work from this lab (Renbaum and Smith, 2009a, b) has suggested that BA forms supercooled particles when made this way, as evidenced by differences in the uptake kinetics and relative product yields depending on whether solidification is induced by pre-cooling the particles in a $-78{ }^{\circ} \mathrm{C}$ bath or not. With a melting point much closer to room temperature, 2-ODA is also believed to exist as supercooled droplets. Furthermore, no difference in the kinetics or the product yields is observed when 2-ODA particles are pre-cooled indicating no phase change (i.e. the particles remained supercooled). What is more, when bulk samples $(\sim 10 \mathrm{~g})$ of 2-ODA were melted in a beaker and allowed to cool to room temperature, they remained liquid for several hours. The viscosity of the supercooled liquid appeared similar to the warm, melted 2-ODA, and it is inferred that the supercooled droplets are good surrogates for liquid droplets. The squalane, 2-ODA, and BA particle sizes were typically $180-220 \mathrm{~nm}(\mathrm{gsd}=1.20-1.24), 45$ $120 \mathrm{~nm}$ (gsd $=1.2-1.3$ ), and $90-100 \mathrm{~nm}(\mathrm{gsd}=1.2-1.3)$, respectively, as measured using a scanning mobility particle sizer (SMPS) consisting of a DMA (TSI, Inc. model 3081) and CPC (model 3785, TSI, Inc.). 


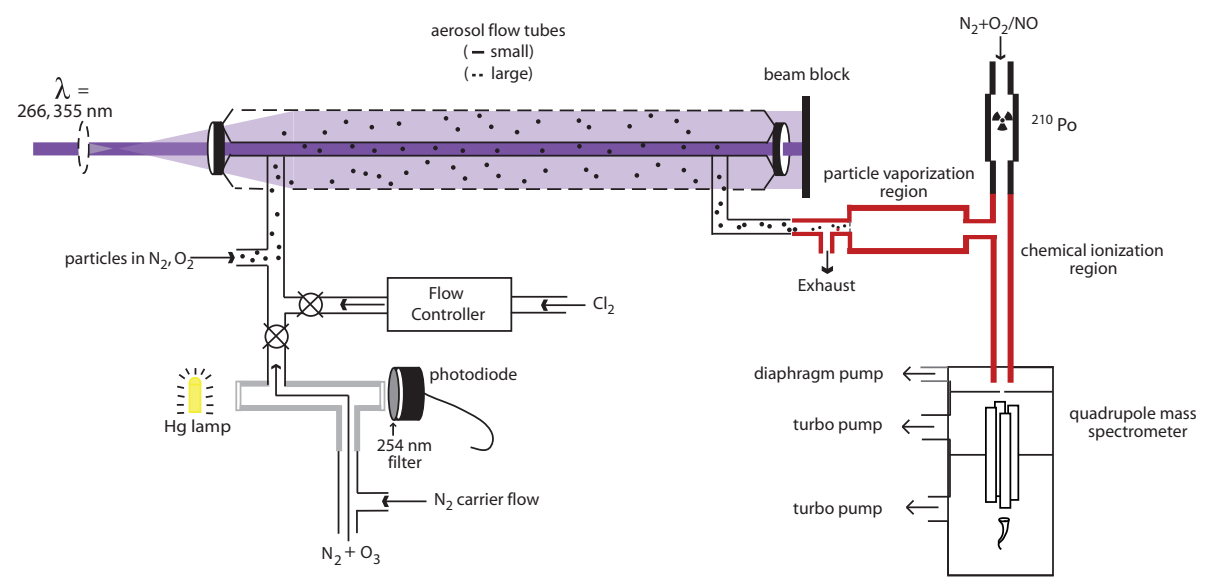

Fig. 1. Schematic diagram of the experimental setup to collect particle kinetic decays with: (1) fixed reaction time of $2 \mathrm{~s}$ (small flow tube) or (2) variable reaction time up to $66 \mathrm{~s}$ (large flow tube). The chemical ionization schemes used for particle and gas-phase reference detection are described in the text.

\subsection{Flow tube reactions}

A schematic of the experimental setup is shown in Fig. 1. After particle generation, the particles entered one of two flow tube reactors along with $\mathrm{N}_{2}, \mathrm{O}_{2}, \mathrm{O}_{3}$ or $\mathrm{Cl}_{2}$ and a gas-phase reference species. Hydroxyl radicals were generated by photodissociation of $\mathrm{O}_{3}$ using the fourth harmonic $(266 \mathrm{~nm})$ from a 10-Hz pulsed Nd:YAG laser (QuantaRay PRO-250, Spectra-Physics), and residual water vapor in the apparatus was sufficient to react with $\mathrm{O}\left({ }^{1} \mathrm{D}\right)$ to generate $\mathrm{OH}$ radicals:

$\mathrm{O}_{3}+h v \rightarrow \mathrm{O}\left({ }^{1} \mathrm{D}\right)+\mathrm{O}_{2}$

$\mathrm{O}\left({ }^{1} \mathrm{D}\right)+\mathrm{H}_{2} \mathrm{O} \rightarrow 2 \mathrm{OH}$

Chlorine radicals were generated by photodissociation of $\mathrm{Cl}_{2}$ using the third harmonic $(355 \mathrm{~nm})$ of the same laser. The radical concentration is believed to have remained nearly constant between laser shots because reactions with the gasphase reference species, the precursor species and the radicals, themselves, are not sufficiently fast (on the timescale of 100 milliseconds) to cause a significant depletion of the radicals. The concentrations of $\mathrm{OH}$ or $\mathrm{Cl}$ radicals generated were varied by changing either the concentration of $\mathrm{O}_{3}$ or $\mathrm{Cl}_{2}$ or the Nd:YAG laser fluence. The concentration of $\mathrm{O}_{3}$ in the carrier flow was determined by Beer's Law in a UV absorption cell equipped with a UV pen lamp (254 nm) and a photodiode detector with a $254 \mathrm{~nm}$ filter and corrected for dilution upon meeting the particle and $\mathrm{O}_{2}$ flows. For the $\mathrm{Cl}_{2}$ concentration dependence experiments, the concentration of $\mathrm{Cl}_{2}$ in the flow tube was calculated from the flow of $\mathrm{Cl}_{2}$ from a lecture bottle of known concentration.

Reactions were carried out at atmospheric pressure and $293 \mathrm{~K}$ in two separate glass flow tubes with the dimensions $1.1 \mathrm{~cm}$ i.d. $\times 90.0 \mathrm{~cm}$ length and $5.1 \mathrm{~cm}$ i.d. $\times 91.4 \mathrm{~cm}$ length, and will be referred to from this point forward as the "small" and "large" flow tubes, respectively. Upon exiting the flow tube, gas and particle phase species were analyzed by an Aerosol Chemical Ionization Mass Spectrometer. For the $\mathrm{OH}$ experiments, Sq or 2-ODA aerosols (0.9 slpm $\mathrm{N}_{2}$ flow), $\mathrm{O}_{2}$ $(0.125 \mathrm{slpm}$ for the small flow tube and $0.100 \mathrm{slpm}$ for the large flow tube) and gas-phase reference ( $\leq 1 \mathrm{sccm}$, standard cubic centimeter per minute) were introduced into one inlet port of the flow tube reactor. Ozone, the $\mathrm{OH}$ precursor, was generated using a commercial ozone generator (Model L11, Pacific Ozone Technology) and stored on silica gel at $-80^{\circ} \mathrm{C}$. By passing a small flow $(5-10 \mathrm{sccm})$ of $\mathrm{N}_{2}$ over the trapped $\mathrm{O}_{3}$ and then diluting the $\mathrm{O}_{3}$ in a $\mathrm{N}_{2}$ carrier flow (1.48 slpm for the small flow tube and $0.7 \mathrm{slpm}$ for the large flow tube), $\mathrm{O}_{3}$ was introduced into the second inlet port of the flow tube reactor. The total flow of $1.7 \mathrm{slpm}$ for the large flow tube and $2.5 \mathrm{slpm}$ for the small flow tube thus contained 5-6\% $\mathrm{O}_{2}$. For the $\mathrm{Cl}$ experiments, $\mathrm{Sq}$, BA or 2-ODA particles, $\mathrm{N}_{2}$ carrier flow and $\mathrm{O}_{2}$ were added as described above, but $\mathrm{Cl}_{2}$ was added as the radical precursor instead of $\mathrm{O}_{3}$, and the $1.7 \mathrm{slpm}$ and $2.5 \mathrm{slpm}$ flows for the large and small flow tubes contained $20 \% \mathrm{O}_{2}$. Based on the total flow velocity and the volumes of the two flow tubes, the total reactant interaction times were $2 \mathrm{~s}$ and $66 \mathrm{~s}$ for the small and large flow tubes, respectively.

For the small flow tube, the beam from the Nd:YAG laser (beam diameter $=\sim 1 \mathrm{~cm}$ ) was directed down the axis of the flow tube so that the volume of the flow tube was filled with light during the experiments. For the large flow tube, a convex quartz lens with a focal length of $6 \mathrm{~cm}$ was positioned so that the beam would expand to approximately one inch in diameter as it passed through the one-inch window and then continue to expand to fill the flow tube within $\sim 4 \mathrm{~cm}$ of entering the flow tube. The integrated $\mathrm{OH}$ exposure, $[\mathrm{OH}]_{\mathrm{avg}} t$, was determined using mixed-phase relative rates (Hearn and 
Smith, 2006; Hartz et al., 2007) with gas-phase references of methanol $\left(k_{\mathrm{OH}}=9.0( \pm 0.8) \times 10^{-13} \mathrm{~cm}^{3}\right.$ molecule $\left.{ }^{-1} \mathrm{~s}^{-1}\right)$ (Picquet et al., 1998) and 2-hexanol $\left(k_{\mathrm{OH}}=1.21\right.$ $( \pm 0.07) \times 10^{-11} \mathrm{~cm}^{3}$ molecule $\mathrm{s}^{-1}$ ) (Wallington et al., 1988 ) for the reactions of squalane and 2-ODA particle reactions, respectively. Acetone- $\mathrm{d}_{1}$ was used as the gas-phase reference for $\mathrm{Sq}+\mathrm{Cl}$, and its rate constant was measured previously in this lab $\left(k_{\mathrm{Cl}}=1.83\right.$ $( \pm 0.28) \times 10^{-12} \mathrm{~cm}^{3}$ molecule $\left.{ }^{-1} \mathrm{~s}^{-1}\right)$ (unpublished). Acetone $\left(k_{\mathrm{Cl}}=2.07( \pm 0.31) \times 10^{-12} \mathrm{~cm}^{3}\right.$ molecule $\left.{ }^{-1} \mathrm{~s}^{-1}\right)$ (Zhao et al., 2008) was used as the gas-phase reference for the $2-\mathrm{ODA}+\mathrm{Cl}$ and $\mathrm{BA}+\mathrm{Cl}$ reactions. Because the uptake coefficients were calculated by measuring the particle reaction relative to a gas-phase reference reaction, wall loss of the radicals affected each equally and was not a factor. The use of light to initiate the reaction also meant that the measurements were insensitive to wall losses of the particles and the gas-phase reference because those losses do not change upon introduction of the light.

\subsection{Collection of particle decay data in the two flow tubes}

Use of the small flow tube for studying heterogeneous reactions between gas-phase radicals and organic aerosols has been described in detail elsewhere (Hearn et al., 2007; Renbaum and Smith, 2009a, b). In summary, the reaction time $(\sim 2 \mathrm{~s})$ is too short to enable the collection of many data points as the aerosol species concentration decays as a function of time. For this reason, in order collect particle decay data, the radical concentration must be changed either continuously or in discrete steps by adjusting the power of the photodissociation laser or the concentration of the radical precursor. In doing so, it is assumed that changing the radical concentration is equivalent to changing the reaction time in reaching a given radical exposure. The large flow tube used here, however, allows the observation of particle and gas-phase reference decays as a function of time at nearlyconstant radical concentration as the particles and gas-phase species exit the flow tube. This "virtual injector" flow tube method will be described in detail in an upcoming paper from this lab. In short, upon introduction of the photodissociation laser either $\mathrm{OH}$ or $\mathrm{Cl}$ is produced throughout the flow tube and the reaction begins; particles nearest the end of the flow tube exit first with the least amount of time to react with the radical species, while those furthest from the exit of the flow tube have the longest time (66s) to react. Thus, particle decay data were collected:

1. As a function of radical concentration at fixed time in the small flow tube.

2. As a function of time at a fixed radical concentration in the large flow tube.

The goals of these experiments are to determine if the two methods of measuring kinetics yield the same result in both gas-phase and heterogeneous relative rates experiments and to infer from these results whether radical concentration and time are interchangeable variables in studying particle oxidation kinetics. In order to best compare the particle decay data obtained with each flow tube, the $\mathrm{OH}$ or $\mathrm{Cl}$ concentration in each flow tube was adjusted so that $\sim 20 \%$ of the particle-phase species reacted away over the course of each experiment. Reactions in the small flow tube were performed by discrete measurements where the $\mathrm{O}_{3}$ or $\mathrm{Cl}_{2}$ concentration and laser power were set so that upon introducing the laser light into the flow tube, the particle phase species would react by $\sim 20 \%$. By alternately turning on and off the laser source into the flow tube, the particle phase and gas-phase reference signal were obtained before, during, and after each reaction.

Because the particles have much more time to react with the $\mathrm{OH}$ or $\mathrm{Cl}$ radicals in the large flow tube it was necessary to use smaller radical concentrations so that after the 66 s residence time only $\sim 20 \%$ of the particle phase species had reacted. This was achieved by adjusting the amount of $\mathrm{O}_{3}$ or $\mathrm{Cl}_{2}$ entering the flow tube and the laser power was maintained at the same laser power used in the reactions in the small flow tube above. For the $\mathrm{O}_{3}$ and $\mathrm{Cl}_{2}$ concentration dependence experiments, the $\mathrm{O}_{3}$ and $\mathrm{Cl}_{2}$ concentrations were fixed and the laser fluence was adjusted in order to reach equivalent radical concentrations in each flow tube.

\subsection{Chemical ionization and detection}

The flow tube eluent containing aerosol and gas-phase references was sampled into the mass spectrometer through a stainless steel orifice $(0.5 \mathrm{mmi}$.d. $)$ in a heated $\left(180^{\circ} \mathrm{C}\right)$ stainless steel vaporizer tube (1/4 inch o.d., 4 inches long). The vaporized aerosol flow then entered the heated $\left(150^{\circ} \mathrm{C}\right)$ stainless steel ion tube ( $1 / 2$ inch o.d., 8 inches long, 40 Torr) of the CIMS instrument where it mixed with a 2 slpm flow of $\mathrm{N}_{2}$ containing $\mathrm{H}^{+}\left(\mathrm{H}_{2} \mathrm{O}\right)_{n}$ (where $n=2,3$ ) or $\mathrm{NO}^{+}$reagent ions generated from a radioactive ${ }^{210} \mathrm{Po}$ source (NRD). When $\mathrm{H}^{+}\left(\mathrm{H}_{2} \mathrm{O}\right)_{n}$ ions were used for ionization, small amounts of $\mathrm{O}_{2}$ were added to the flow through the ${ }^{210}$ Po source in order to increase the $\mathrm{H}^{+}\left(\mathrm{H}_{2} \mathrm{O}\right)_{n}$ ion signal by approximately a factor of two.

For the reactions of 2-ODA and 2-hexanol with $\mathrm{OH}$ and for the reactions of 2-ODA, BA and acetone with $\mathrm{Cl}$, proton transfer from $\mathrm{H}^{+}\left(\mathrm{H}_{2} \mathrm{O}\right)_{n}$ was used to generate protonated molecular ions. Squalane particles were detected through hydride abstraction and the acetone- $\mathrm{d}_{1}$ gas-phase reference (for the reaction with $\mathrm{Cl}$ ) was detected via $\mathrm{NO}^{+}$-adduct formation, both using $\mathrm{NO}^{+}$ions. Methanol, the gas-phase reference used for the $\mathrm{OH}+\mathrm{Sq}$ reaction, is not efficiently ionized by $\mathrm{NO}^{+}$and thus in order to determine the $\mathrm{OH}$ exposure after a $\mathrm{Sq}$ particle reaction, ionization was rapidly changed to proton transfer via $\mathrm{H}^{+}\left(\mathrm{H}_{2} \mathrm{O}\right)_{n}$ by replacing the NO through the ${ }^{210} \mathrm{Po}$ with $\mathrm{O}_{2}$ and the decay was repeated at the same laser fluence and $\mathrm{O}_{3}$ flow. This method was repeated approximately ten times and the time between recording respective 
squalane and methanol decays (the time required to change ionization schemes) was typically $0.5-1 \mathrm{~min}$.

The ions generated as described above were then sampled into the high vacuum region through a $200-\mu \mathrm{m}$ orifice by means of a small potential gradient $(2-5 \mathrm{~V})$ and differential pumping. Ions were filtered using a quadrupole mass spectrometer (ABB Extrel) and detected using a Channeltron electron multiplier (model 4816, Burle).

\subsection{Gases and chemicals}

Gases used were: $\mathrm{N}_{2}$ (99.99\%, National Welders), $\mathrm{O}_{2}$ (industrial grade, National Welders), and NO (CP grade, National Welders). Flows were measured and maintained using mass flow controllers (MKS). 2-hexanol, methanol and acetone were purchased from Sigma Aldrich and had purities greater than $99 \%$. Squalane $(>99 \%)$ and brassidic acid $(\sim 99 \%)$ were purchased from Sigma Aldrich and MP Biomedicals, respectively, and 2-octyldodecanoic acid (2ODA) was provided by Jarchem Industies, Inc. (Newark, $\mathrm{NJ})$.

\section{Results and discussion}

\subsection{Reactive uptake experiments in the small and large flow tubes}

Reactions between $\mathrm{OH}$ and $\mathrm{Sq}$ and 2-ODA aerosols and between $\mathrm{Cl}$ and Sq, 2-ODA and BA aerosols were studied in each flow tube. The concentration of the $\mathrm{O}_{3}$ or $\mathrm{Cl}_{2}$ radical precursor was adjusted in order to reach the same extent of reaction in each flow tube while maintaining a constant laser fluence. The effective reactive uptake coefficients for the gas-particle reactions were calculated using the following equation (Hearn and Smith, 2006):

$\gamma_{\text {part }}=\left[\frac{d\left([\text { Part }] /[\text { Part }]_{0}\right)}{d([\text { radical }] \cdot t)}\right] \frac{4 R T}{\bar{c}} \frac{V}{S_{A}}[\text { Part }]_{0}$.

Here, $\gamma_{\text {part }}$ is the effective reactive uptake coefficient of $\mathrm{OH}$ or $\mathrm{Cl}$ in the aerosol particle as measured from the rate of loss of the aerosol species. The [radical] term is the concentration of $\mathrm{OH}$ or $\mathrm{Cl}, \mathrm{V} / \mathrm{S}_{\mathrm{a}}(=d / 6)$ is the volume to surface area ratio of the particles determined using the surface-area-weighted particle size data from the SMPS, $R$ is the gas constant, $T$ is the temperature, $\bar{c}$ is the mean speed of $\mathrm{OH}$ or $\mathrm{Cl}$, and [Part $]_{0}$ is the initial concentration of Sq, 2-ODA, or BA in the unreacted particles. The term in brackets represents the slope of the initial decay of the particle-phase species with respect to radical exposure $(=$ [radical $t)$ which is determined from the measured fractional loss of the gas-phase reference species, $[\mathrm{ref}] /[\mathrm{ref}]_{0}$ :

$([$ radical $] \cdot t)=-\frac{1}{k} \ln \left(\frac{[\text { ref }]}{[\text { ref }]_{0}}\right)$ where $k$ is the rate constant of the reaction of the reference species with $\mathrm{OH}$ or $\mathrm{Cl}$. For the small flow tube measurements, the slope of the initial decay in Eq. (1) is approximated by the discrete change:

$\frac{d\left([\text { Part }] /[\text { Part }]_{0}\right)}{d([\text { radical }] \cdot t)} \cong \frac{\Delta\left([\text { Part }] /[\text { Part }]_{0}\right)}{\Delta([\text { radical }] \cdot t)}$.

The calculated uptake coefficients do not include a correction for limitation by gas-phase diffusion of the $\mathrm{OH}$ or $\mathrm{Cl}$ radicals. This correction was neglected because: (1) it is negligible for $\mathrm{OH}$ diffusion $(<10 \%$ with an $\mathrm{OH}$ diffusion coefficient in air of $0.22 \mathrm{~cm}^{2} \mathrm{~s}^{-1}$ (Ivanov et al., 2007)), and (2) it is not clear how to correct for $\mathrm{Cl}$ diffusion when the observed rate of reaction includes secondary chemistry (indicated here by $\left.\gamma_{\text {part }}>1\right)$. Furthermore, the conclusions drawn about the dependence of the uptake coefficients on $\mathrm{O}_{3}$ or $\mathrm{Cl}_{2}$ concentration are not influenced by whether or not the gas-phase diffusion correction is made.

Sample decays of 2-ODA aerosol particles as a function of $\mathrm{OH}$ and $\mathrm{Cl}$ exposure in the two reactor flow tubes are shown in Fig. 2a and b, respectively. Here, the uncertainty bars for the small flow tube measurements made in a stepwise fashion with and without the light are derived from the $2 \sigma$ of the 2-ODA and gas-phase reference measurements averaged for one minute. The reactions in the large flow tube were made by following the losses of the 2-ODA and gasphase reference in a continuous manner, and so estimates of the uncertainties were not made on the individual points; instead, the $3 \sigma$ uncertainty of the slope associated with the fit is estimated and shown as the range of slopes representing the uncertainty on the associated uptake coefficient. From repeated measurements, the average $\gamma_{\text {part }}$ for reactive uptake of $\mathrm{OH}$ with 2-ODA and $\mathrm{Sq}$ particles and the reactive uptake of $\mathrm{Cl}$ with 2-ODA, squalane and BA particles were determined and are displayed in Fig. 3a and $b$ as a function of the average radical concentration, respectively.

The data in Fig. 3a show that in the two flow tube experiments, where different $\mathrm{OH}$ concentrations were needed to reach the same nominal exposure, the effective reactive uptake coefficient, $\gamma_{\text {part }}$, increases with decreasing $\mathrm{OH}$ concentration. This trend is consistent with the results of Che et al. (2009) and Smith et al. (2009) for $\mathrm{OH}+\mathrm{Sq}$ aerosols, also shown in Fig. 3a, in which the effective uptake coefficient was larger for the longer-residence-time $(1.5-3 \mathrm{~h})$ experiments relative to the shorter-residence-time (37 s) experiments. The data in Fig. 3b, on the other hand, show that for the reaction with $\mathrm{Cl}$ radicals the effective reactive uptake coefficient increases with decreasing $\mathrm{Cl}$ concentration. At first glance, then, it appears as if the rates of reaction are somehow related to the radical concentration implying that experiments conducted by varying reaction time are not equivalent to those conducted by changing the radical concentration. While other studies have also measured the rate of $\mathrm{OH}$ and $\mathrm{Cl}$ uptake by organic particles recently, these results are not included in Fig. 3 because they used solid particles (Lambe 

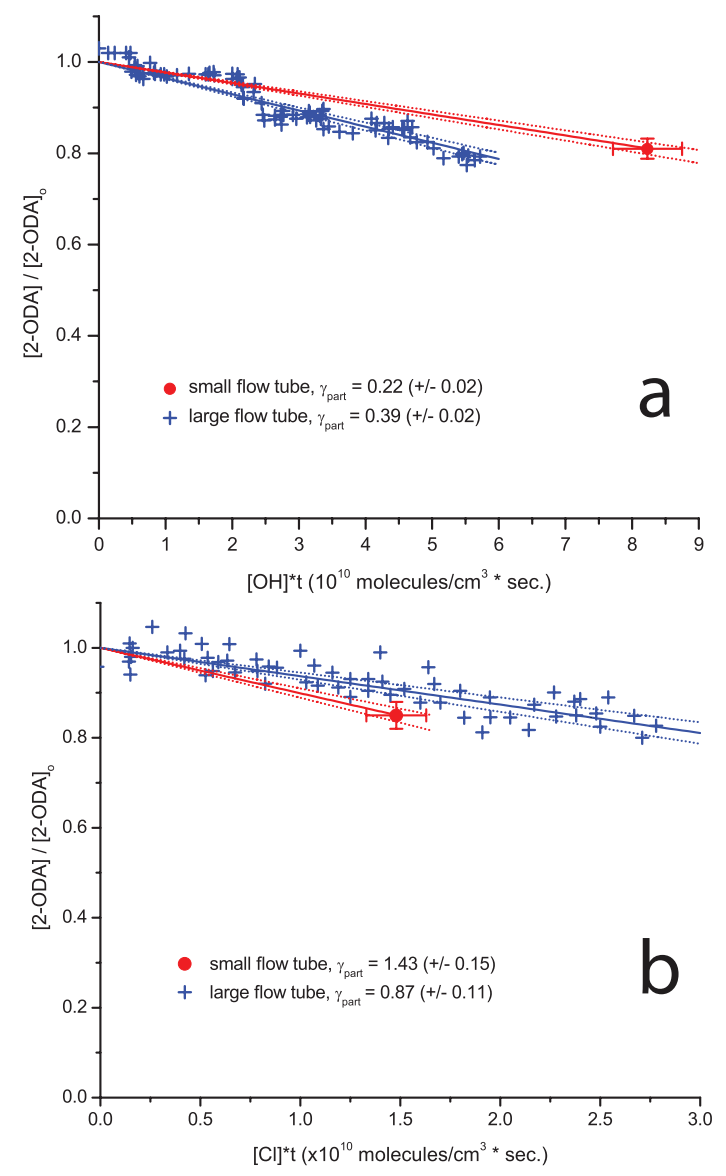

Fig. 2. (a) Sample 2-ODA particle decays from small and large flow tubes. For the examples shown, $\gamma_{\text {part }}$ for $\mathrm{OH}$ on 2-ODA particles were 0.22 ( $50 \mathrm{~nm}$ particles) and 0.39 (58 $\mathrm{nm}$ particles) for the small and large flow tubes, respectively. (b) Sample 2-ODA particle decays from small and large flow tubes. For the examples shown, $\gamma_{\text {part }}$ for $\mathrm{Cl}$ on 2-ODA particles were 1.43 (52 $\mathrm{nm}$ particles) and 0.87 (58 $\mathrm{nm}$ particles) for the small and large flow tubes, respectively. These reactive uptake coefficients were not corrected for limitation of uptake by gas phase diffusion.

et al., 2007; McNeill et al., 2008), mixed particles for which uptake coefficients are difficult to define (Weitkamp et al., 2008) or may have included secondary chemistry which can be a complicated function of $[\mathrm{OH}]$ or $[\mathrm{Cl}]$ (George et al., 2007; Hearn and Smith, 2006; Hearn et al., 2007).

To investigate the apparent dependence on radical concentration, several measurements of the relative rates of just gas-phase species with $\mathrm{OH}$ and $\mathrm{Cl}$ were made as well, and it was found that no such discrepancy was observed between the small and large flow tubes. For example, for the $\mathrm{OH}$ reactions the rate of 1-butanol relative to that of 2-hexanol was measured to be $0.63( \pm 0.07)$ and $0.61( \pm 0.04)$ in the small and large flow tubes, respectively, compared to a ratio of $0.72( \pm 0.07)$ calculated from published rate constants of these reactions (1-butanol:
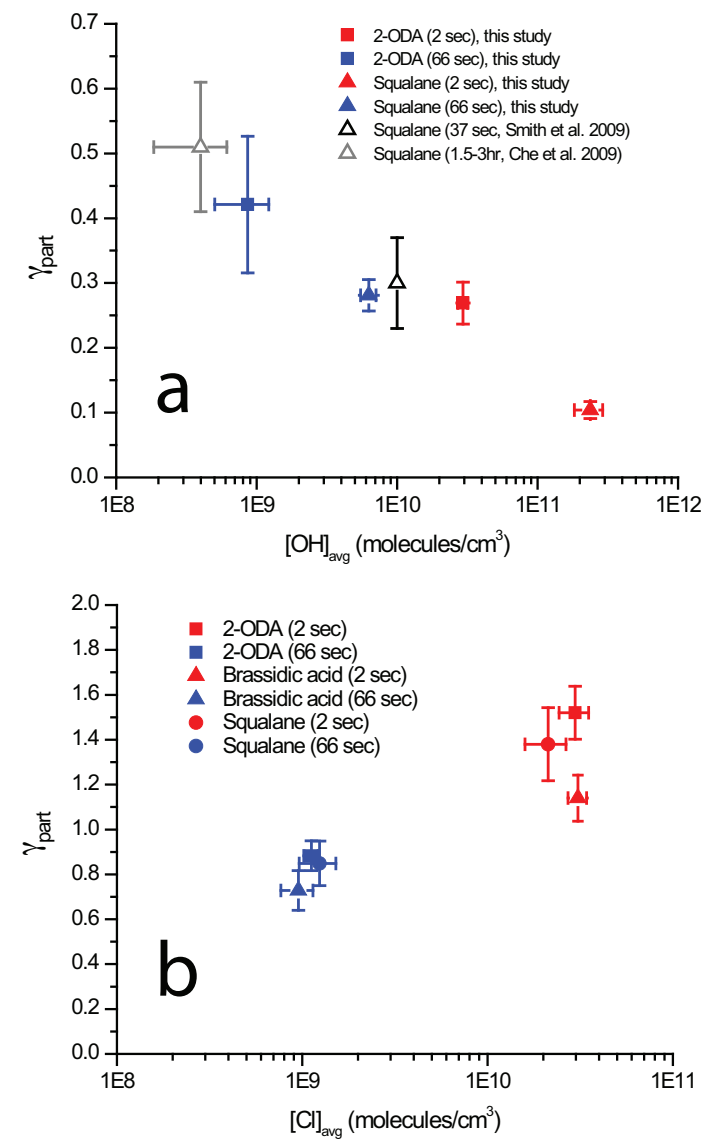

Fig. 3. (a) Effective reactive uptake coefficient, $\gamma_{\text {part }}$, of $\mathrm{OH}$ on 2ODA particles and Sq particles in the large and small flow tubes as a function of $\mathrm{OH}$ concentration. The data of Che et al. (2009) and Smith et al. (2009) are shown for comparison. (b) Effective reactive uptake coefficient, $\gamma_{\text {part }}$, of $\mathrm{Cl}$ on 2-ODA, Sq, and BA particles in the large and small flow tubes as a function of $\mathrm{Cl}$ concentration.

$k_{\mathrm{OH}}=8.66 \times 10^{-12} \mathrm{~cm}^{3}$ molecule ${ }^{-1} \mathrm{~s}^{-1}$, Wu et al., 2003; 2hexanol: $k_{\mathrm{OH}}=1.21 \times 10^{-11} \mathrm{~cm}^{3}$ molecule ${ }^{-1} \mathrm{~s}^{-1}$, Wallington et al., 1988). Thus, it appears as if only the rates of the gas-particle reactions, and not the gas-phase-only reactions, are influenced by the radical concentrations. However, it must be noted that in these experiments not only were the radical concentrations different in the two flow tubes, but so were the concentrations of the precursors $\left(\mathrm{O}_{3}\right.$ for $\mathrm{OH}$ and $\mathrm{Cl}_{2}$ for $\mathrm{Cl}$ ); a higher concentration of precursor was used in the small flow tube to generate a higher concentration of the radical. What effect, if any, does the precursor concentration have on the radical uptake kinetics?

\subsection{Rate of reaction of 2-ODA with $\mathrm{OH}$ with $\left[\mathrm{O}_{3}\right]$ held constant}

To explore the effects of $\mathrm{O}_{3}$ and $\mathrm{Cl}_{2}$ concentrations on the reactive uptake of $\mathrm{OH}$ and $\mathrm{Cl}$, respectively, systematic experiments were carried out using 2-ODA particles. Brassidic 


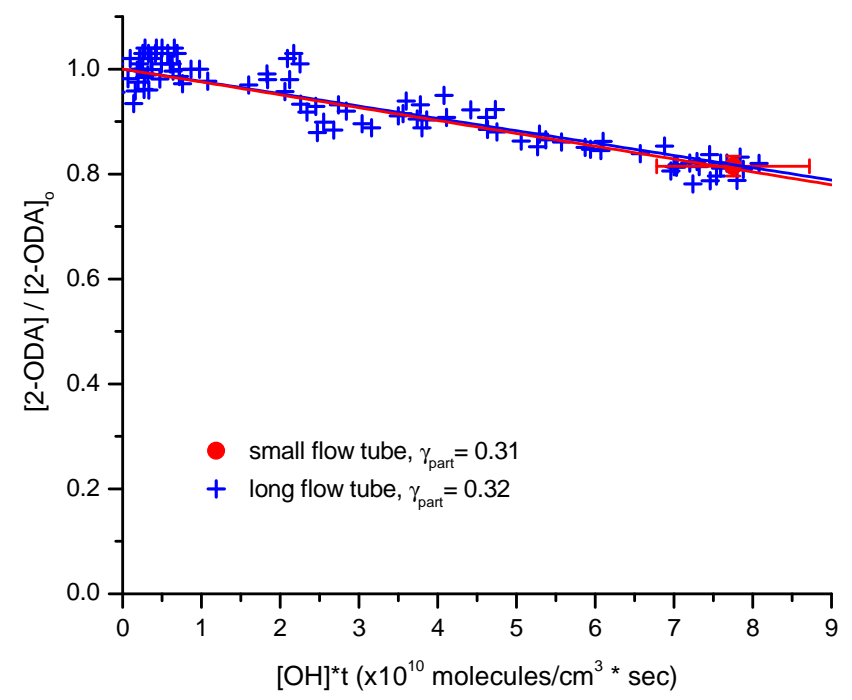

Fig. 4. 2-ODA decay from reaction with $\mathrm{OH}$ in the small and large flow tubes with $\left[\mathrm{O}_{3}\right]=3-4 \times 10^{15}$ molecules $\mathrm{cm}^{-3}$.

acid particles were not chosen for this study since BA contains a double bond and thus undergoes reactions with $\mathrm{O}_{3}$, the $\mathrm{OH}$ precursor. Squalane particles were not used because the squalane $+\mathrm{OH}$ experiments are relatively timeconsuming since different chemical ionization schemes are used to observe the reaction of the squalane (using $\mathrm{NO}^{+}$) and methanol, the gas-phase reference species (using $\mathrm{H}^{+}\left(\mathrm{H}_{2} \mathrm{O}\right)_{n}$ ) (see Sect. 2.4). For these reasons, 2-ODA particles were chosen to investigate the effects of precursor species on the reactive uptake of $\mathrm{OH}$ and $\mathrm{Cl}$.

The reaction of 2-ODA with $\mathrm{OH}$ was performed in the small and large flow tubes using the fluence of the photodissociation laser to control the amount of $\mathrm{OH}$ production at fixed $\mathrm{O}_{3}$ concentrations. Generally, the laser fluence was adjusted such that the 2-ODA reacted by approximately $20 \%$ over the length of each flow tube. As before, 2-hexanol was used as the gas-phase reference. The results of one such experiment, where the concentration of $\mathrm{O}_{3}$ was $3-4 \times 10^{15}$ molecules $\mathrm{cm}^{-3}$ are shown in Fig. 4. Now, when $\mathrm{O}_{3}$ concentration is the same in the two flow tubes, $\gamma_{\text {part }}$ is nearly the same despite the fact that the reaction times and $[\mathrm{OH}]$ differed by a factor of 33: $\gamma_{\text {part }}=0.31$ and 0.32 for the small and large flow tubes, respectively. In other words, $[\mathrm{OH}]$ and time are truly interchangeable parameters in these gas-particle kinetics experiments as long as the $\mathrm{O}_{3}$ concentration is fixed. These results suggest that $\mathrm{O}_{3}$ is affecting the particle reaction kinetics in some way warranting a systematic study as a function of $\mathrm{O}_{3}$ concentration.

\subsection{Rate of reaction of 2-ODA with $\mathrm{OH}$ as a function of $\left[\mathrm{O}_{3}\right]$}

To better understand the effect that $\mathrm{O}_{3}$ has on the rate of reaction of 2-ODA particles with $\mathrm{OH}, \gamma_{\text {part }}$ was mea-

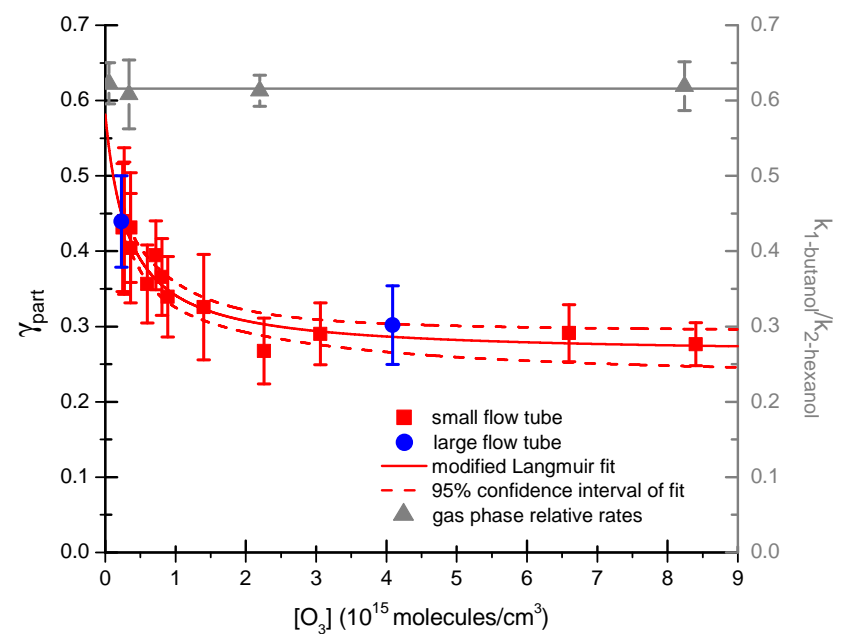

Fig. 5. Effective reactive uptake coefficient, $\gamma_{\text {part }}$, of $\mathrm{OH}$ on 2ODA particles as a function of $\mathrm{O}_{3}$ concentration. The Langmuirtype adsorption isotherm used to fit the data, Eq. (4), is also shown with $95 \%$ confidence intervals. The best fit parameters are: $\gamma_{0}=$ $0.56( \pm 0.07), K=2.60( \pm 1.40) \times 10^{-15} \mathrm{~cm}^{3}$ molecule ${ }^{-1}$, and $f=$ $1.86( \pm 0.16)$. Also shown are the results of a gas-phase relative rates experiment in which the ratio of the rate constants of 1-butanol and 2-hexanol reacting with $\mathrm{OH}$ was determined as a function of $\left[\mathrm{O}_{3}\right]$.

sured as a function of $\mathrm{O}_{3}$ concentration in the small and large flow tubes (Fig. 5). In these experiments, the laser fluence was used to control $[\mathrm{OH}]$ at a fixed $\mathrm{O}_{3}$ concentration which ranged from $2.7 \times 10^{14}$ molecules $\mathrm{cm}^{-3}$ to $8.3 \times 10^{15}$ molecules $\mathrm{cm}^{-3}$. The reactive uptake coefficient initially decreases with increasing $\left[\mathrm{O}_{3}\right]$ and then reaches a plateau where a further increase in $\left[\mathrm{O}_{3}\right]$ has no effect on the reactive uptake of $\mathrm{OH}$. In order to ensure that this trend was not due to a change in the reactivity of the gas-phase reference species, a gas-phase relative rates experiment using the reactions of 1-butanol $+\mathrm{OH}$ and 2-hexanol $+\mathrm{OH}$ was performed as a function of $\mathrm{O}_{3}$ concentration (grey triangles in Fig. 5). No variation in the ratio of the rate constants was observed across the range of ozone concentrations used indicating that the trend observed in the 2-ODA uptake coefficient is, indeed, specific to the particles.

The uptake coefficient data in Fig. 5 are fit well by a Langmuir-type isotherm with the form:

$\gamma=\gamma_{0}\left(1-\frac{\theta}{f}\right)$.

where $\gamma_{0}$ corresponds to the uptake coefficient in the absence of $\mathrm{O}_{3}, f$ is an adjustable parameter which accounts for the incomplete inhibition of the rate of reaction even at the highest values of $\left[\mathrm{O}_{3}\right]$, and $\theta$ is the fractional surface coverage of $\mathrm{O}_{3}$ :

$\theta=\frac{K\left[\mathrm{O}_{3}\right]}{1+K\left[\mathrm{O}_{3}\right]}$, 
where $K$ is the $\mathrm{O}_{3}$ adsorption/desorption equilibrium constant. The fact that this modified Langmuir function fits the data in Fig. 5 well suggests that $\mathrm{O}_{3}$ is adsorbing to the particle surface where it affects the observed rate of reaction of 2-ODA with $\mathrm{OH}$. If $\mathrm{O}_{3}$ were simply diffusing into the bulk of the particle, it would be difficult to explain how the observed rate of reaction would initially decrease with increasing $\left[\mathrm{O}_{3}\right]$ and then level off because most of the $\mathrm{O}_{3}$ would reside inside the particle and not at the surface. The best fit parameters are: $\gamma_{\mathrm{o}}=0.56( \pm 0.07), K=2.60$ $( \pm 1.40) \times 10^{-15} \mathrm{~cm}^{3}$ molecule ${ }^{-1}, f=1.86( \pm 0.16)$.

The value of $\gamma_{0}=0.56$ represents the predicted effective uptake coefficient in the absence of any inhibition by adsorbed $\mathrm{O}_{3}$. Very few experiments exist in which the reactive uptake coefficient of $\mathrm{OH}$ on organic films or particles has been measured in the absence of $\mathrm{O}_{3}$ to which $\gamma_{\mathrm{o}}$ can be compared. In one such study, Bagot et al. (2008) have determined the reactive uptake of $\mathrm{OH}$ on squalane films using 355-nm laser photolysis of a low pressure of $\mathrm{HONO}$ to generate $\mathrm{OH}$ above the squalane surface. In that study, the reactive uptake coefficient of $\mathrm{OH}$ on squalane films was $0.49 \pm 0.04$ which is comparable to the value of $\gamma_{\mathrm{o}}=0.56( \pm 0.07)$ reported here for 2-ODA aerosols. Likewise, these values are similar to the results of Che et al. (2009) in which $\gamma=0.51$ was measured for reaction of squalane particles with $\mathrm{OH}$ over a timescale of $1.5-3 \mathrm{~h}$ using a presumably low concentration of $\mathrm{O}_{3}$ to generate $\mathrm{OH}$, though this concentration was not measured.

The adsorption/desorption equilibrium constant of $\mathrm{O}_{3}$ on the 2-ODA particle surface deduced from the Langmuir fit in Fig. 5 is $K=2.6( \pm 1.4) \times 10^{-15} \mathrm{~cm}^{3}$ molecule ${ }^{-1}$ and is comparable to the adsorption/desorption equilibrium constant obtained from experiments of $\mathrm{O}_{3}$ adsorption on other organic surfaces (Mmereki and Donaldson, 2003; Kwamena et al., 2004, 2007; Mmereki et al., 2004). In particular, Kwamena et al. (2007) describe the Langmuir-Hinshelwood adsorption of $\mathrm{O}_{3}$ on various liquid organic aerosols, and for supercooled liquid azelaic acid aerosols they report a value of $K=2.2 \times 10^{-15} \mathrm{~cm}^{3}$ molecule ${ }^{-1}$. This good agreement is not surprising, as both the azelaic acid particles used in that study and the 2-ODA aerosols used here are supercooled liquid organic carboxylic acid particles.

The parameter $f$ in the modified Langmuir function used to fit the data is a measure of the degree to which the reactive uptake coefficient is affected by the presence of $\mathrm{O}_{3}$ at the particle surface. A value of $f=1$ would represent a Langmuir adsorption isotherm for which the reaction is completely inhibited at saturation (when $\theta=1$ ), whereas a value of $f>1$ represents incomplete inhibition even at saturation. In the fit to the data in Fig. 5, the value of $f$ is $1.86( \pm 0.16)$ indicating that when $\mathrm{O}_{3}$ has reached its surface saturation concentration, the reaction between $\mathrm{OH}$ and 2-ODA still proceeds at $54 \%(=1 / 1.86)$ of the rate if $\mathrm{O}_{3}$ were absent $\left(\gamma_{0}\right)$. This partial hindrance of the reaction could be due to: (1) the existence of a layer of $\mathrm{O}_{3}$ that acts as a barrier between $\mathrm{OH}$ and the 2-ODA particle surface which slows but does not inhibit the reaction, (2) the incomplete coverage of the surface by $\mathrm{O}_{3}$ islands or other such phenomena whereby $\mathrm{OH}$ can still react with 2-ODA that is not covered by $\mathrm{O}_{3}$, or (3) the formation of long-lived reactive oxygen intermediates (ROI's) from the interaction of $\mathrm{O}_{3}$ with the particle surface as suggested recently by Shiraiwa et al. (Shiraiwa et al., 2011).

An $\mathrm{O}_{3}$ layer may act as either a physical barrier, where only $\mathrm{OH}$ that is able to diffuse through the $\mathrm{O}_{3}$ layer may react with 2-ODA, or a chemical barrier which reacts with $\mathrm{OH}$ to form $\mathrm{HO}_{2}$. From gas-phase rate constants of $\mathrm{OH}$ and $\mathrm{HO}_{2}$ reactions with analogous organic species (Lloyd, 1974; Ohta, 1984; Atkinson et al., 1982; Gierczak and Ravishankara, 2000) it is expected that the conversion of $\mathrm{OH}$ to $\mathrm{HO}_{2}$ would slow considerably, if not halt entirely, the reactive loss of 2-ODA. The formation of island-like structures of $\mathrm{O}_{3}$ would be feasible if $\mathrm{O}_{3}$ self-adsorption is favored relative to $\mathrm{O}_{3}$ adsorption to the 2-ODA surface once a critical concentration of $\mathrm{O}_{3}$ exists at the surface. Alternatively, the formation of ROI's with lifetimes much longer than $\mathrm{O}_{3}$ has recently been suggested by Shiraiwa and co-workers (Shiraiwa et al., 2011) to be formed from the interaction of $\mathrm{O}_{3}$ with aromatic surfaces. While the mechanism of formation of ROI's from interaction of $\mathrm{O}_{3}$ with a saturated organic acid surface as used here is unclear, it is possible that ROI's are formed and could affect the observed dependence of the effective reactive uptake coefficient on $\mathrm{O}_{3}$ concentrations. As no change in particle signal was observed upon the addition of $\mathrm{O}_{3}$ even at the highest $\mathrm{O}_{3}$ concentrations used here, any ROI's formed here must be unreactive with the 2-ODA particles or be formed in low yields. If formed in sufficient yields to block reactive sites of $\mathrm{OH}$ on the particle surface, ROI's may participate in the decrease in $\mathrm{OH}$ reactive uptake with increasing $\mathrm{O}_{3}$.

\subsection{Rate of reaction of 2-ODA with $\mathrm{Cl}$ as a function of $\left[\mathrm{Cl}_{2}\right]$}

Unlike the reaction of $\mathrm{OH}$ with 2-ODA, for which the rate of reaction decreased at higher $\mathrm{OH}$ concentration, it was found that the apparent uptake coefficient for the $\mathrm{Cl}$ reaction with 2-ODA increased with $\mathrm{Cl}$ concentration (Fig. 3b). Is it possible that this trend is related to the concentrations of $\mathrm{Cl}_{2}$ used in those experiments in a similar way that the rate of $\mathrm{OH}$ reaction was influenced by the concentration of $\mathrm{O}_{3}$ ? To investigate this possibility, $\gamma_{\text {part }}$ was measured as a function of $\mathrm{Cl}_{2}$ concentration (shown in Fig. 6) with the laser fluence adjusted in each experiment to achieve approximately $20 \%$ reaction of the 2-ODA. Experiments were conducted in both the small flow tube and in the large flow tube, and it was found that the effective reactive uptake coefficients are equal at a given $\mathrm{Cl}_{2}$ concentration even though $[\mathrm{Cl}]$ and reaction time differed by a factor of 33 in the two flow tubes. Thus, $[\mathrm{Cl}]$ and time are equivalent and interchangeable variables in measuring the reactive uptake of $\mathrm{Cl}$ on 2-ODA particles for a given $\mathrm{Cl}_{2}$ concentration. 


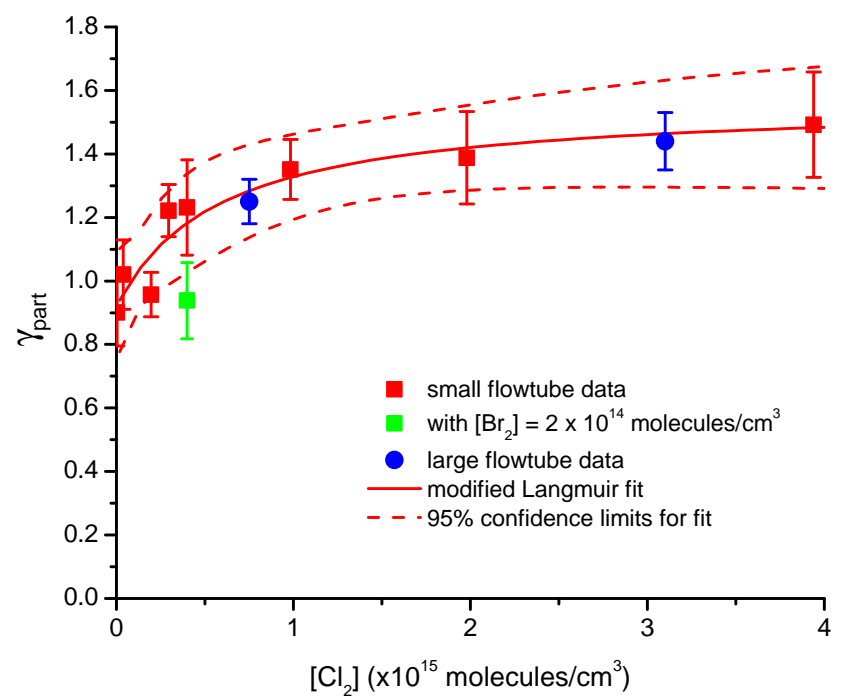

Fig. 6. Effective reactive uptake coefficient, $\gamma_{\text {part }}$, for $\mathrm{Cl}$ on $2-$ ODA particles as a function of $\mathrm{Cl}_{2}$ concentration. The Langmuirtype adsorption isotherm used to fit the data, Eq. (4), is also shown with $95 \%$ confidence intervals. The best fit parameters are: $\gamma_{\mathrm{o}}=$ $0.92( \pm 0.07), K=1.72( \pm 1.23) \times 10^{-15} \mathrm{~cm}^{3}$ molecule ${ }^{-1}$, and $f=$ $-1.42( \pm 0.30) . \mathrm{Br}_{2}$ adsorption decreases the observed rate of reaction.

As seen in Fig. 6, the reactive uptake coefficient increases with increasing $\left[\mathrm{Cl}_{2}\right]$ and then reaches a plateau where a further increase in $\left[\mathrm{Cl}_{2}\right]$ has little to no effect on the observed rate of reaction. As with the $\mathrm{OH}$ uptake dependence experiments, these data are well represented by a Langmuirtype isotherm (Eq. 4) with: $\gamma_{\mathrm{o}}=0.92( \pm 0.07), K=1.72$ $( \pm 1.23) \times 10^{-15} \mathrm{~cm}^{3}$ molecule ${ }^{-1}$, and $f=-1.42( \pm 0.30)$. To ensure that the observed change in the rate of 2-ODA reaction was not due to a change in the reactivity of the gas-phase reference species, a gas-phase relative rates experiment of $\mathrm{Cl}+$ methanol and $\mathrm{Cl}+\mathrm{n}$-propanol was performed. The ratio of the rate constants was measured to be $2.62( \pm 0.16)$, in good agreement with the ratio of $2.91\left(-0.59^{+0.74}\right)$ calculated from the values recommended in the IUPAC Gas Kinetic Data Evaluation (Atkinson et al., 2006). The fact that the ratio is independent of $\left[\mathrm{Cl}_{2}\right]$ indicates that the trend observed in the 2-ODA uptake coefficient is, indeed, specific to the particles.

The observed Langmuir-type dependence indicates that $\mathrm{Cl}_{2}$ is adsorbing to the surface of the particle with a concomitant enhancement in the rate of loss of 2-ODA. The most likely cause of this enhancement is from a radical chain mechanism in which the alkyl radicals $(\mathrm{R})$ formed from the initial reaction of $\mathrm{Cl}+2$-ODA react with $\mathrm{Cl}_{2}$ to reform a $\mathrm{Cl}$ radical and an alkylchloride product, $\mathrm{RCl}$. In fact, evidence for the formation of the $\mathrm{RCl}$ product is observed by the appearance of a peak at $m / z=347 \mathrm{amu}\left(\left[(2-\mathrm{ODA}-\mathrm{H}+\mathrm{Cl}) \mathrm{H}^{+}\right]\right)$ in the mass spectrum (not shown). The $\mathrm{Cl}$ radical that is formed from the $\mathrm{R}+\mathrm{Cl}_{2}$ reaction can then react with an- other 2-ODA molecule thereby enhancing its rate of loss. In essence, there is a higher $\mathrm{Cl}$ concentration at the surface than is calculated based on the gas-particle collision rate derived from the measured rate of loss of the gas-phase reference, and this increases the effective uptake coefficient. This secondary loss of 2-ODA also explains why effective uptake coefficients greater than one are measured. Further evidence for this radical chain mechanism was observed in reactions carried out in the absence of $\mathrm{O}_{2}$ in which the effective uptake coefficient was measured to be as high as 10 (not shown), presumably because the competitive $\mathrm{R}+\mathrm{O}_{2}$ reaction was eliminated allowing the chain to propagate to a larger extent. The value of the uptake coefficient in the absence of the enhancement from the adsorbed $\mathrm{Cl}_{2}$ can be estimated from the $\gamma_{\mathrm{o}}$ parameter obtained from the Langmuir isotherm fit: $\gamma_{\mathrm{o}}=0.92( \pm 0.07)$. Thus, the reaction between $\mathrm{Cl}$ radicals from the gas phase and the 2-ODA occurs at nearly the gasparticle collision rate, consistent with analogous reactions in the gas phase which typically occur near the gas-kinetic collision rate (Atkinson et al., 2006). The parameter $f$ in the Langmuir fit represents the degree to which the rate of 2ODA reaction increases or decreases because of the adsorbed $\mathrm{Cl}_{2}$. The best fit value for $f$ is $-1.42( \pm 0.30)$ indicating that the adsorbed $\mathrm{Cl}_{2}$ enhances the rate of 2-ODA loss (because $f<0)$ by a factor of $70 \%(=1 / 1.42)$, which is effectively a measure of the radical chain length.

The adsorption/desorption equilibrium constant of $\mathrm{Cl}_{2}$ on the 2-ODA particle surface deduced from the Langmuir fit in Fig. 6 is $K=1.72( \pm 1.23) \times 10^{-15} \mathrm{~cm}^{3}$ molecule ${ }^{-1}$. There is currently a lack of adsorption/desorption coefficients in the literature for $\mathrm{Cl}_{2}$ on organic surfaces, but as there are no chemical reactions (and thus no chemisorption) between $\mathrm{Cl}_{2}$ and 2-ODA, adsorption is due to physisorption. $\mathrm{Ph}-$ ysisorption is expected even for nonpolar adsorbents on nonpolar surfaces because of the attraction of the instantaneous dipole moments in the surface species and adsorbent arising from the instantaneous positions of the nuclei and electrons. For adsorbent species with near-zero permanent dipole moments, such as $\mathrm{Cl}_{2}$ and $\mathrm{O}_{3}$, the attraction to a mostly nonpolar surface such as 2-ODA (although 2-ODA is slightly polar due to the presence of a carboxylic acid moiety, the long carbon chains are essentially nonpolar) is expected to result in physisorption of $\mathrm{Cl}_{2}$ and/or $\mathrm{O}_{3}$ to the particle surface. Because the permanent dipole moments of $\mathrm{O}_{3}$ and $\mathrm{Cl}_{2}$ are on the same order of magnitude, it is expected that the $\mathrm{Cl}_{2}$ adsorption/desorption coefficient would be similar to that of $\mathrm{O}_{3}$, which was measured in the $\mathrm{OH}$ experiments to be $K=2.60( \pm 1.40) \times 10^{-15} \mathrm{~cm}^{3}$ molecule ${ }^{-1}$. Thus, the adsorption/desorption equilibrium constant obtained from the modified Langmuir isotherm for $\mathrm{Cl}_{2}$ on 2-ODA, $K=1.72$ $( \pm 1.23) \times 10^{-15} \mathrm{~cm}^{3}$ molecule ${ }^{-1}$, is reasonable.

It may seem counterintuitive that a lightweight, volatile halogen, $\mathrm{Cl}_{2}$, would adsorb to the surface of a liquid 2-ODA particle instead of dissolving in it. To further investigate the plausibility of this, experiments were performed in which 
$\mathrm{Br}_{2}$ was added to the flow tube along with $\mathrm{Cl}_{2}$ to determine whether $\mathrm{Br}_{2}$ would adsorb and affect the rate of 2-ODA loss. $\mathrm{Br}_{2}$ was used to decouple the effect of adsorption from the radical reactions since the $\mathrm{Br}$ radicals generated by photolysis of $\mathrm{Br}_{2}$ should not react with the gas-phase reference, acetone, or the particles; for example, the $\mathrm{Br}+$ acetone rate constant is estimated to be only $1.0 \times 10^{-20} \mathrm{~cm}^{3}$ molecule ${ }^{-1} \mathrm{~s}^{-1}$ at $298 \mathrm{~K}$ (King et al., 1970), and reactions between $\mathrm{Br}$ and gas-phase organic compounds are typically orders of magnitude slower than analogous reactions with $\mathrm{Cl}$ (Bierbach et al., 1996; Finlayson-Pitts et al., 1999; Ezell et al., 2002). In fact, no reaction of the 2-ODA particles is observed in the absence of $\mathrm{Cl}_{2}$ indicating that, indeed, $\mathrm{Br}$ radicals do no react with 2-ODA to an appreciable extent. $\mathrm{Br}_{2}$ does react with $\mathrm{Cl}$ radicals decreasing the $\mathrm{Cl}$ concentration, but this decrease affects both the particles and the gas-phase reference species and should not alter the measurement of the rate of particle reaction. However, the $\mathrm{Br}_{2}$ is expected to interact with the surface in a similar way as $\mathrm{Cl}_{2}$ does thereby providing a probe of surface adsorption. The effective uptake coefficient measured from the 2-ODA loss decreased from $\gamma=1.23$ in the absence of $\mathrm{Br}_{2}$ to $\gamma=0.94$ in the presence of $2 \times 10^{14}$ molecules $\mathrm{cm}^{-3}$ of $\mathrm{Br}_{2}$ (Fig. 6 open square), a statistically-significant difference at the $99 \%$ confidence level. This decrease could have resulted from either or both of two possibilities: (1) $\mathrm{Br}_{2}$ at the surface "deactivates" the $\mathrm{Cl}$ radicals by reacting with them:

$\mathrm{Cl}+\mathrm{Br}_{2} \rightarrow \mathrm{BrCl}+\mathrm{Br}$,

or (2) $\mathrm{Cl}_{2}$ is displaced by $\mathrm{Br}_{2}$ at the surface thereby reducing the significance of the $\mathrm{R}+\mathrm{Cl}_{2}$ reaction in the radical chain mechanism. Either way, the decrease observed in the 2-ODA reactivity indicates that $\mathrm{Br}_{2}$ has adsorbed to the particle surface, and by extension implies that the $\mathrm{Cl}_{2}$ adsorption inferred from the Langmuir-type plot (Fig. 6) is reasonable. While it would have been interesting to study this effect as a function of $\left[\mathrm{Br}_{2}\right]$ to see if $\mathrm{Br}_{2}$ also saturates the surface, it was not possible to increase it without adversely influencing the $\mathrm{H}^{+}\left(\mathrm{H}_{2} \mathrm{O}\right)_{n}$ reagent ion signal.

Very recently, Liu et al. (2011) have measured the uptake of $\mathrm{Cl}$ radicals by squalane particles and found that time and $[\mathrm{Cl}]$ are not interchangeable kinetic parameters because of secondary radical chain chemistry. In that work, they found that the uptake coefficient increased directly proportionally to $\left[\mathrm{Cl}_{2}\right]$, just as is observed in the present work, albeit at a slower rate, over the same range of $\left[\mathrm{Cl}_{2}\right](0-$ $8 \times 10^{14}$ molecules $\left.\mathrm{cm}^{-3}\right)$. It is possible that Liu et al. (2011) did not observe the plateau demonstrated in Fig. 6 simply because they did not use a large enough $\left[\mathrm{Cl}_{2}\right]$. They also found that the uptake coefficient depends inversely proportionally on $[\mathrm{Cl}]$, and from this they conclude that time and $[\mathrm{Cl}]$ are not interchangeable. Such a dependence is not observed in the present study as long as the $\left[\mathrm{Cl}_{2}\right]$ is controlled and does not vary, perhaps because the secondary chemistry is less significant in the 2-ODA particles compared to the squalane particles for some reason. Otherwise, an explanation for the discrepancy between the two studies is not apparent.

\section{Implications and conclusions}

No difference is observed in the reaction kinetics of 2-ODA aerosols with $\mathrm{OH}$ or $\mathrm{Cl}$ when the decay profiles are constructed by changing the radical concentration (small flow tube) or the reaction time (large flow tube) as long as the precursor $\left(\mathrm{O}_{3}\right.$ or $\left.\mathrm{Cl}_{2}\right)$ concentration is the same in both cases. Thus, it is appropriate to consider the radical concentration and reaction time as interchangeable parameters with the product of the two, the exposure $(=[\mathrm{OH}] \cdot t$ or $[\mathrm{Cl}] \cdot t)$, being conserved. Consequently, it seems reasonable to extrapolate results from laboratory aerosol flow tube studies, in which reactions are studied with high radical concentrations on the timescales of seconds to minutes, to atmospheric processes, which involve much lower radical concentrations and occur over several days to a few weeks.

However, it has also been observed that the rates of reaction are functions of the concentrations of the precursor species, $\mathrm{O}_{3}$ or $\mathrm{Cl}_{2}$. It was inferred from these dependencies that these species affect the reactivity of the radicals by adsorbing to the surface of the liquid particles. This finding has implications for many gas-particle uptake experiments since high concentrations of precursors are almost always required to carry out the reactions on the seconds-minutes timescale. For example, in the case of $\mathrm{OH}$ reaction with 2-ODA particles, extrapolation of the high- $\left[\mathrm{O}_{3}\right]$ uptake coefficients to the atmosphere, where $\mathrm{O}_{3}$ concentrations rarely exceed $250 \mathrm{ppbv}$ (Kleinman et al., 2002) (still 50 times smaller than the smallest concentration used here) would underestimate the rate by $50 \%$. The only way to determine the magnitude of this artifact is to carry out a systematic study as a function of $\mathrm{O}_{3}$ concentration.

The adsorption of $\mathrm{O}_{3}$ is also believed to be responsible for the slower rate of reaction observed for squalane in the small flow tube $(\gamma=0.10)$ compared to the large flow tube $(\gamma=0.28)$ (Fig. 3a) where higher $\left[\mathrm{O}_{3}\right]$ was used in the small flow tube. Interestingly, $\mathrm{O}_{3}$ adsorption may also explain the range of values reported by Wilson and co-workers (Che et al., 2009; Smith et al., 2009) for the reaction of $\mathrm{OH}+$ squalane in which they also used $\mathrm{O}_{3}$ photolysis to generate $\mathrm{OH}$ (shown for comparison in Fig. 3a); in an aerosol flow tube study (with a residence time of $37 \mathrm{~s}$ ), they report a value of $\gamma=0.30$, and in a continuous flow stirred tank reactor (residence time of 1.5-3 h), they report a higher value of $\gamma=0.51$. It seems reasonable that they probably used a larger $\mathrm{O}_{3}$ concentration in the shorter flow tube study and that $\mathrm{O}_{3}$ adsorption resulted in a smaller uptake coefficient, but $\mathrm{O}_{3}$ concentrations were not reported in either study. Likewise, the effect that $\mathrm{Cl}_{2}$ has on the rate of reaction with $\mathrm{Cl}$ radicals does not seem to be unique to reactions with 2-ODA particles; the effective uptake coefficients measured for brassidic 
acid and squalane particles were also approximately $50 \%$ larger with high $[\mathrm{Cl}]$ (and high $\left[\mathrm{Cl}_{2}\right]$ ) in the small flow tube as compared to with low $[\mathrm{Cl}]$ (and low $\left[\mathrm{Cl}_{2}\right]$ ) in the large flow tube (Fig. 3). Thus, adsorption of both $\mathrm{O}_{3}$ and $\mathrm{Cl}_{2}$ precursors appears to occur regardless of particle composition, at least in these studies, and must be taken into account in similar experiments.

In the atmosphere, $\mathrm{O}_{3}$ concentrations are orders of magnitude smaller than those for which adsorption effects were observed to be significant in this study. However, if volatile species such as $\mathrm{O}_{3}$ and $\mathrm{Cl}_{2}$ exhibit a Langmuir-type adsorption on the surfaces of organic particles, it seems reasonable that other inert gas-phase species present at much higher concentrations in the troposphere may demonstrate similar behavior. Perhaps $\mathrm{N}_{2}, \mathrm{O}_{2}, \mathrm{Ar}, \mathrm{H}_{2} \mathrm{O}$ or $\mathrm{CO}_{2}$, for example, adsorb to the surface of particles and influence rates of gasparticle reactions. In fact, indirect evidence for the adsorption of $\mathrm{O}_{2}$ to liquid dioctyl sebacate (DOS) particles was observed previously in this lab (Hearn et al., 2007). In that study, $\mathrm{Cl}$ radicals reacted with DOS particles, and the yield of the ketone product initially increased with increasing $\left[\mathrm{O}_{2}\right]$ and then approached an asymptote at higher $\left[\mathrm{O}_{2}\right](\mathrm{Fig} .7 \mathrm{in}$ that paper, Hearn et al., 2007). The dependence on $\left[\mathrm{O}_{2}\right]$ was described well by a Langmuir-type functional form, and it was inferred that a reaction to create the ketone product was occurring at the surface of the particles:

$\mathrm{RO}+\mathrm{O}_{2} \rightarrow$ ketone $+\mathrm{HO}_{2}$.

However, the effect that $\mathrm{O}_{2}$ had on the rate of reaction was not measured, and further work is required to determine whether species such as $\mathrm{O}_{2}, \mathrm{~N}_{2}$ and $\mathrm{H}_{2} \mathrm{O}$ might influence rates of gas-particle reactions under tropospheric conditions.

This work has shown that radical concentration and time can be considered interchangeable parameters in laboratory studies of gas-particle kinetics. However, it has also demonstrated that rates of gas-particle reactions can be influenced dramatically by the adsorption of inert species such as $\mathrm{O}_{3}$ and $\mathrm{Cl}_{2}$. This effect may not be specific to $\mathrm{O}_{3}$ and $\mathrm{Cl}_{2}$, and the high concentrations of other precursors that are often used in laboratory studies may also alter the gas-particle kinetics. For example, HONO photolysis can also be used to generate $\mathrm{OH}$ radicals, but it is not clear to what extent HONO adsorbs to particle surfaces and how it modifies the uptake kinetics. Clearly, careful consideration of the high concentrations of precursor species used to create radical species in the laboratory must be made in order to accurately extrapolate laboratory results to the troposphere. Finally, this study has examined only single-component, model liquid particles. Likely, the extent and importance of adsorption is dependent on the chemical and physical properties of the particles, but more work is needed to explore this.
Acknowledgements. The authors gratefully acknowledge support for this research from the National Science Foundation (AGS0547011) and the National Aeronautics and Space Administration (NNX06AE86G) as well as JarChem Industries for supplying the 2-octyldodecanoic acid used in this study.

Edited by: M. Ammann

\section{References}

Andreae, M. O. and Crutzen, P. J.: Atmospheric aerosols: biogeochemical sources and role in atmospheric chemistry, Science, 276, 1052-1058, 1997.

Atkinson, R., Aschmann, S. M., Carter, W. P. L., and Pitts, J. N.: Rate Constants for the gas-phase reaction of $\mathrm{OH}$ radicals with a series of ketones at $299+/-2$ K, Int. J. Chem. Kinet., 14, 839847, 1982.

Atkinson, R., Baulch, D. L., Cox, R. A., Crowley, J. N., Hampson, R. F., Hynes, R. G., Jenkin, M. E., Rossi, M. J., Troe, J., and IUPAC Subcommittee: Evaluated kinetic and photochemical data for atmospheric chemistry: Volume II - gas phase reactions of organic species, Atmos. Chem. Phys., 6, 3625-4055, doi:10.5194/acp-6-3625-2006, 2006.

Avol, E. L., Jones, M. P., Bailey, R. M., Chang, N. M. N., Kleinman, M. T., Linn, W. S., Bell, K. A., and Hackney, J. D.: Controlled exposures of human volunteers to sulfate aerosols - Health-effects and aerosol characterization, Am. Rev. Respir. Dis., 120, 319-327, 1979.

Bagot, P. A. J., Waring, C., Costen, M. L., and McKendrick, K. G.: Dynamics of inelastic scattering of $\mathrm{OH}$ Radicals from reactive and inert liquid surfaces, J. Phys. Chem. C, 112, 10868-10877, 2008.

Baumer, D., Vogel, B., Versick, S., Rinke, R., Mohler, O., and Schnaiter, M.: Relationship of visibility, aerosol optical thickness and aerosol size distribution in an ageing air mass over South-West Germany, Atmos. Environ., 42, 989-998, 2008.

Bertram, A. K., Ivanov, A. V., Hunter, M., Molina, L. T., and Molina, M. J.: The reaction probability of $\mathrm{OH}$ on organic surfaces of tropospheric interest, J. Phys. Chem. A, 105, 9415-9421, 2001.

Bierbach, A., Barnes, I., and Becker, K. H.: Rate coefficients for the gas-phase reactions of bromine radicals with a series of alkenes, dienes, and aromatic hydrocarbons at 298+/-2 K, Int. J. Chem. Kinet., 28, 565-577, 1996.

Chang, S.-P. and Miwa, T. K.: Brassidic acid: Preparation from erucic acid and mechanism of elaidinization, J. Am. Oil Chem. Soc., 49, 422-425, 1972.

Charlson, R. J., Lovelock, J. E., Andreae, M. O., and Warren, S. G. Sulfate aerosols and climate, Nature, 340, 437-438, 1989.

Che, D. L., Smith, J. D., Leone, S. R., Ahmed, M., and Wilson, K. R.: Quantifying the reactive uptake of $\mathrm{OH}$ by organic aerosols in a continuous flow stirred tank reactor, Phys. Chem. Chem. Phys., 11, 7885-7895, 2009.

Cooper, P. L. and Abbatt, J. P. D.: Heterogeneous interactions of $\mathrm{OH}$ and $\mathrm{HO}_{2}$ radicals with surfaces characteristic of atmospheric particulate matter, J. Phys. Chem., 100, 2249-2254, 1996.

Eidels-Dubovoi, S.: Aerosol impacts on visible light extinction in the atmosphere of Mexico City, Sci. Total Environ., 287, 213220, 2002. 
Ezell, M. J., Wang, W., Ezell, A. A., Soskin, G., and FinlaysonPitts, B. J.: Kinetics of reactions of chlorine atoms with a series of alkenes at $1 \mathrm{~atm}$ and $298 \mathrm{~K}$ : structure and reactivity, Phys. Chem. Chem. Phys., 4, 5813-5820, 2002.

Finlayson-Pitts, B. J., Keoshian, C. J., Buehler, B., and Ezell, A. A.: Kinetics of reaction of chlorine atoms with some biogenic organics, Int. J. Chem. Kinet., 31, 491-499, 1999.

George, I. J., Vlasenko, A., Slowik, J. G., Broekhuizen, K., and Abbatt, J. P. D.: Heterogeneous oxidation of saturated organic aerosols by hydroxyl radicals: uptake kinetics, condensed-phase products, and particle size change, Atmos. Chem. Phys., 7, 4187-4201, doi:10.5194/acp-7-4187-2007, 2007.

Gierczak, T. and Ravishankara, A. R.: Does the $\mathrm{HO}_{2}$ radical react with ketones?, Int. J. Chem. Kinet., 32, 573-580, 2000.

Hartz, K. E. H., Weitkamp, E. A., Sage, A. M., Donahue, N. M., and Robinson, A. L.: Laboratory measurements of the oxidation kinetics of organic aerosol mixtures using a relative rate constants approach, J. Geophys. Res.-Atmos., 112, D04204, doi:10.1029/2006jd007526, 2007.

Hearn, J. D. and Smith, G. D.: A mixed-phase relative rates technique for measuring aerosol reaction kinetics, Geophys. Res. Lett., 33, L17805, doi:10.1029/2006GL026963, 2006.

Hearn, J. D., Renbaum, L. H., Wang, X., and Smith, G. D.: Kinetics and products from reaction of $\mathrm{Cl}$ radicals with dioctyl sebacate (DOS) particles in $\mathrm{O}_{2}$ : a model for radical-initiated oxidation of organic aerosols, Phys. Chem. Chem. Phys., 9, 4803-4813, 2007.

Hobbs, P. V.: Aerosol-cloud-climate interactions, International Geophysics, 54, Academic Press, San Diego, xii, 235 pp., 1993.

Ivanov, A. V., Trakhtenberg, S., Bertram, A. K., Gershenzon, Y. M., and Molina, M.J.: $\mathrm{OH}, \mathrm{HO}_{2}$, and ozone gaseous diffusion coefficients, J. Phys. Chem. A, 111, 1632-1637, 2007.

Kessler, S. H., Smith, J. D., Che, D. L., Worsnop, D. R., Wilson, K. R., and Kroll, J. H.: Chemical Sinks of Organic Aerosol: Kinetics and Products of the Heterogeneous Oxidation of Erythritol and Levoglucosan, Environ. Sci. Technol., 44, 7005-7010, 2010.

King, K. D., Golden, D. M., and Benson, S. W.: Kinetics of gasphase thermal bromination of acetone - Heat of formation and stabilization energy of acetonyl radical, J. Am. Chem. Soc., 92, 5541-5546, 1970.

Kleinman, L. I., Daum, P. H., Imre, D., Lee, Y.-N., Nunnermacker, L. J., Springston, S. R., Weinstein-Lloyd, J., and Rudolph, J.: Ozone production rate and hydrocarbon reactivity in 5 urban areas: A cause of high ozone concentration in Houston, Geophys. Res. Lett., 29, 1467, doi:10.1029/2001GL014569, 2002.

Knothe, G.: Synthesis, applications, and characterization of Guerbet compounds and their derivatives, Lipid Technology, 14, 101104, 2002.

Kwamena, N.-O. A., Thornton, J. A., and Abbatt, J. P. D.: Kinetics of surface-bound benzo[a]pyrene and ozone on solid organic and salt aerosols, J. Phys. Chem. A, 108, 11626-11634, 2004.

Kwamena, N. O. A., Staikova, M. G., Donaldson, D. J., George, I. J., and Abbatt, J. P. D.: Role of the aerosol substrate in the heterogeneous ozonation reactions of surface-bound PAHs, J. Phys. Chem. A, 111, 11050-11058, 2007.

Lambe, A., Zhang, J., Sage, A., and Donahue, N. M.: Controlled $\mathrm{OH}$ Radical Production via Ozone-Alkene Reactions for Use in Aerosol Aging Studies, Environ. Sci. Technol., 41, 2357-2363, 2007.

Liu, C.-N., Smith, J. D., Che, D. L., Ahmed, M., Leone, S. R., and Wilson, K. R.: The direct observation of secondary radical chain chemistry in the heterogeneous reaction of chlorine atoms with submicron squalane droplets, Phys. Chem. Chem. Phys., 13, 8993-9007, 2011.

Lloyd, A. C.: Evaluated and estimated kinetics data for phase reactions of hydroperoxyl radical, Int. J. Chem. Kinet., 6, 169-228, 1974.

McNeill, V. F., Yatavelli, R. L. N., Thornton, J. A., Stipe, C. B., and Landgrebe, O.: Heterogeneous $\mathrm{OH}$ oxidation of palmitic acid in single component and internally mixed aerosol particles: vaporization and the role of particle phase, Atmos. Chem. Phys., 8, 5465-5476, doi:10.5194/acp-8-5465-2008, 2008.

Mmereki, B. T. and Donaldson, D. J.: Direct observation of the kinetics of an atmospherically important reaction at the air-aqueous interface, J. Phys. Chem. A, 107, 11038-11042, 2003.

Mmereki, B. T., Donaldson, D. J., Gilman, J. B., Eliason, T. L., and Vaida, V.: Kinetics and products of the reaction of gas-phase ozone with anthracene adsorbed at the air-aqueous interface, Atmos. Environ., 38, 6091-6103, 2004.

Moise, T. and Rudich, Y.: Uptake of $\mathrm{Cl}$ and $\mathrm{Br}$ by organic surfaces - a perspective on organic aerosols processing by tropospheric oxidants, Geophys. Res. Lett., 28, 4083-4086, 2001.

Molina, M. J., Ivanov, A. V., Trakhtenberg, S., and Molina, L. T.: Atmospheric evolution of organic aerosol, Geophys. Res. Lett. 31, L22104, doi:10.1029/2004GL020910, 2004.

Ohta, T.: Rate constants for the reactions of $\mathrm{OH}$ radicals with alkyl substituted olefins, Int. J. Chem. Kinet., 16, 879-886, 1984.

Ondov, J., Davidson, C., and Solomon, P. A.: Special issue of Aerosol Science and Technology for particulate matter: Atmospheric sciences, exposure, and the fourth colloquium on PM and human health - Preface, Aerosol Sci. Technol., 38, 1-2, 2004.

Park, S. U. and Jeong, J. I.: Direct radiative forcing due to aerosols in Asia during March 2002, Sci. Total Environ., 407, 394-404, 2008.

Park, S. U., Chang, L. S., and Lee, E. H.: Direct radiative forcing due to aerosols in East Asia during a Hwangsa (Asian dust) event observed on 19-23 March 2002 in Korea, Atmos. Environ., 39, 2593-2606, 2005.

Penn, A., Murphy, G., Barker, S., Henk, W., and Penn, L.: Combustion-derived ultrafine particles transport organic toxicants to target respiratory cells, Environ. Health Perspect., 113 , 956-963, 2005.

Picquet, B., Heroux, S., Chebbi, A., Doussin, J.-F., Durand-Jolibois, R., Monod, A., Loirat, H., and Carlier, P.: Kinetics of the reactions of $\mathrm{OH}$ radicals with some oxygenated volatile organic compounds under simulated atmospheric conditions, Int. J. Chem. Kinet., 30, 839-847, 1998.

Putaud, J. P., Raes, F., Van Dingenen, R., Bruggemann, E., Facchini, M. C., Decesari, S., Fuzzi, S., Gehrig, R., Huglin, C., Laj, P., Lorbeer, G., Maenhaut, W., Mihalopoulos, N., Mulller, K., Querol, X., Rodriguez, S., Schneider, J., Spindler, G., ten Brink, H., Torseth, K., and Wiedensohler, A.: European aerosol phenomenology-2: chemical characteristics of particulate matter at kerbside, urban, rural and background sites in Europe, Atmos. Environ., 38, 2579-2595, 2004.

Renbaum, L. H. and Smith, G. D.: The importance of phase in the radical-initiated oxidation of model organic aerosols: reactions of solid and liquid brassidic acid particles, Phys. Chem. Chem. Phys., 11, 2441-2451, 2009a. 
Renbaum, L. H. and Smith, G. D.: Organic nitrate formation in the radical-initiated oxidation of model aerosol particles in the presence of $\mathrm{NO}_{\mathrm{x}}$, Phys. Chem. Chem. Phys., 11, 8040-8047, $2009 \mathrm{~b}$.

Saxena, P. and Hildemann, L. M.: Water-soluble organics in atmospheric particles: A critical review of the literature and application of thermodynamics to identify candidate compounds, J. Atmos. Chem., 24, 57-109, 1996.

Shiraiwa, M., Sosedova, Y., Rouviere, A., Yang, H., Zhang, Y., Abbatt, J. P. D., Ammann, M., Pöschl, U.: The role of long-lived reactive oxygen intermediates in the reaction of ozone with aerosol particles. Nat. Chem., 3, 291-295, 2011.

Smith, J. D., Kroll, J. H., Cappa, C. D., Che, D. L., Liu, C. L., Ahmed, M., Leone, S. R., Worsnop, D. R., and Wilson, K. R.: The heterogeneous reaction of hydroxyl radicals with submicron squalane particles: a model system for understanding the oxidative aging of ambient aerosols, Atmos. Chem. Phys., 9, 3209-3222, doi:10.5194/acp-9-3209-2009, 2009.
Wallington, T. J., Dagaut, P., Liu, R., and Kurylo, M. J.: Rate constants for the gas phase reactions of $\mathrm{OH}$ with $\mathrm{C}_{5}$ through $\mathrm{C}_{7}$ aliphatic alcohols and ethers: Predicted and experimental values, Int. J. Chem. Kinet., 20, 541-547, 1988.

Weitkamp, E., Lambe, A., Donahue, N. M., and Robinson, A. L.: Laboratory Measurements of the Heterogeneous Oxidation of Condensed-Phase Organic Molecular Makers for Motor Vehicle Exhaust., Environ. Sci. Technol., 42, 7950-7956, 2008.

Wu, H., Mu, Y. J., Zhang, X. S., and Jiang, G. B.: Relative rate constants for the reactions of hydroxyl radicals and chlorine atoms with a series of aliphatic alcohols, Int. J. Chem. Kinet., 35, 8187, 2003.

Zhao, Z., Huskey, D. T., Nicovich, J. M., and Wine, P. H.: Temperature-dependent kinetics study of the gas-phase reactions of atomic chlorine with acetone, 2-butanone, and 3-pentanone, Int. J. Chem. Kinet., 40, 259-267, 2008. 